\title{
Improvement of seminal quality and sexual function of men with oligoasthenoteratozoospermia syndrome following supplementation with L-arginine and Pycnogenol ${ }^{\circledR}$
}

\author{
Yoshitomo Kobori ${ }^{1}$, Keisuke Suzuki ${ }^{1}$, Toshiyuki Iwahata ${ }^{1}$, Takeshi Shin ${ }^{1}$, Yuko Sadaoka ${ }^{1}$, \\ Ryo Sato ${ }^{1}$, Kojiro Nishio ${ }^{1}$, Hiroshi Yagi ${ }^{1}$, Gaku Arai ${ }^{1}$, Shigehiro Soh ${ }^{1}$, Hiroshi Okada ${ }^{1}$, \\ Jeffry Michael Strong ${ }^{2}$, Peter Rohdewald ${ }^{3}$ \\ ${ }^{1}$ Department of Urology, Dokkyo Medical University Koshigaya Hospital, Saitama, Japan; \\ ${ }^{2}$ Horphag Research, Cointrin/Geneva, Switzerland; \\ ${ }^{3}$ Institute of Pharmaceutical Chemistry, University of Munster, Munster, Germany.
}

\begin{abstract}
Summary We evaluated the effectiveness of antioxidant co-supplementation therapy using Larginine and Pycnogenol ${ }^{\circledR}$ in Japanese men with oligoasthenozoospermia and mild erectile dysfunction (ED). A total of forty-seven adult males with oligoasthenoteratozoospermia syndrome (OAT) were eligible for enrollment. The effectiveness of supplementation with a combination of L-arginine $690 \mathrm{mg}$ and French maritime pine bark extract (Pycnogenol $^{\circledR}$ ) 60mg for OAT and ED was investigated. The sperm concentration was enhanced significantly after treatment 2 and 4 months $(11.79 \pm 9.86$ to $21.22 \pm 28.17$ and $20.15 \pm 23.99 \times 106 / \mathrm{ml})$. Significant improvements in the International Index of Erectile Function (IIEF) were observed in the total score of IIEF $(57.69 \pm 11.04$ to $59.43 \pm$ 12.57) and domain of Orgasmic Function $(9.01 \pm 1.92$ to $9.34 \pm 1.66)$ after 4 months of treatment. L-arginine acts to increase the production of nitric oxide and Pycnogenol ${ }^{\circledR}$ activates the endothelial nitric oxide synthase and it is a potent antioxidant and inhibitor of inducible nitric oxide synthase. This study suggests that the combination of Pycnogenol $^{\circledR}$ and L-arginine (Edicare ${ }^{\circledR}$ ) is helpful for infertile men to ameliorate simultaneously quality of sperms as well as erectile functions.
\end{abstract}

KEY WORDS: Male infertility; Spermatogenesis, erectile dysfunction, L-arginine, Pycnogenol.

Submitted 1 May 2015; Accepted 30 June 2015

\section{INTRODUCTION}

World-wide about 1 in 7 couples have problems in conceiving. Male infertility is involved in 30-50\% of involuntarily childless couples according to European Guidelines on Male Infertility (1).

A specific investigation on male fertility was performed in Japan. Semen quality of 1559 young Japanese men was evaluated in a large multi-center, cross-sectional study (2). Within this group of men between 18-24 years, $9 \%$ had a lower sperm concentration than 15 mill/ml and $31.9 \%$ produced a total sperm number below $40 \mathrm{mill} / \mathrm{ml}$. These numbers are below the limits given in the WHO manual for Examination and Processing of Human Semen (3). So a significant proportion of men will have a lower chance to achieve fertilization because of their sub-optimal semen quality. There is doubtless a need to enhance male fertility for those men diagnosed to have the Oligoasthenoteratozoospermia syndrome (OAT) (4).

Clinical studies conducted in Europe and USA have confirmed that the proprietary, patented combination of Larginine aspartate and Pycnogenol ${ }^{\circledR}$ French maritime pine bark extract marketed as Prelox ${ }^{\circledR}$ (both trademarks of Horphag Research Ltd.,) can improve mild to moderate erectile dysfunction (ED) and increase quantity and quality of sperms (5).

Pycnogenol is a specific pine bark extract consisting of a concentrate of polyphenols, mainly procyanidins, and is listed in the United States Pharmacopoeia 34 as Maritime Pine Extract (6).

Pycnogenol demonstrates its action to improve ED by activating endothelial nitric oxide synthase (e-NOS), thereby increasing nitric oxide production and promoting vasodilation (7).

A synergistic effect in nitric oxide production is achieved when Pycnogenol is administered in combination with Larginine, the substrate for e-NOS (8). It has been reported that the combination of Pycnogenol and L-arginine may increase testosterone concentration, which is suggested to be a physiologic response secondary to increased sexual activity (9).

A Pycnogenol and L-arginine containing supplement formulated for the Japanese population (Edicare ${ }^{\circledR}$ ) for ED has been tested in Japanese patients specifically and improved after 8 weeks of ingestion the erectile function significantly (10). In the present pilot study the influence of Edicare ${ }^{\circledR}$ on quality of sperms was evaluated. Simultaneously, the influence of the preparation on ED on men with confirmed OAT was investigated. 


\section{Materials AND Methods}

\section{Subjects}

This study was conducted in compliance with the Helsinki Declaration after obtaining the approval of the Ethics Committee of Dokkyo Medical University Koshigaya Hospital. Subjects were selected from 47 outpatients with OAT and mild to moderate ED who had given written informed consent. All presented with infertility after at least 2 years of unprotected intercourse. Male infertility was diagnosed if one or more standard semen parameters were below cutoff levels (sperm concentration $<20 \times 10^{6} / \mathrm{ml}$, sperm motility $<50 \%$, normal morphology $<30 \%$, and/or semen volume based $<2 \mathrm{ml}$ ) based on at least two semen analyses performed 3 months apart to eliminate accidental and possible adverse effects of exogenous factors on spermatogenesis. After providing a complete medical and reproductive history exploring all aspects that might be related to fertility, patients underwent physical examination and serum chemical and hematological laboratory tests. Testicular volume was measured using a punched orchidometer.

Serum follicle stimulating hormone, luteinizing hormone, and testosterone levels were measured in all patients (Table 1).

Subjects who did not meet the following 12 exclusion criteria were selected: Habitual consumption of medication and/or a food supplement intended for ED improvement; habitual consumption of medication and /or food supplement that contained either L-arginine, aspartic acid or maritime pine bark extract; allergy to the substances investigated in this study; participation in another clinical study at the start of the study; existence of diabetes mellitus, heart disease, renal disease, hepatic disease, moderate or severe hypertension; habitual consumption of any food supplement to improve the circulation; body mass index (BMI) $\geq 35 \mathrm{kgm}^{2}$; receiving concurrent dental treatment; reported smoking 20 or more cigarettes a day; morning erection achieved most days. Those judged by the investigator (on the basis of laboratory test value or other reasons) as inappropriate for participation in this study were also excluded.

Table 1.

Characteristics of the patients.

\begin{tabular}{|c|c|c|c|}
\hline \multicolumn{2}{|l|}{ Characteristics } & Range & Mean \pm SD \\
\hline \multicolumn{2}{|l|}{ Age } & $26-48$ & $36 \pm 9$ \\
\hline \multicolumn{2}{|l|}{ Age of wife } & $22-44$ & $34 \pm 8$ \\
\hline \multirow[t]{3}{*}{ Serum hormones: } & Testosterone (ng/dl) & $169-988$ & $464 \pm 151$ \\
\hline & LH (IU/I) & 1.1-11.5 & $4.9 \pm 2.8$ \\
\hline & FSH (IU/I) & $1.6-26.8$ & $1.6-26.8$ \\
\hline \multicolumn{4}{|c|}{ Testicular volume (ml): } \\
\hline & Right & $8-26$ & $18 \pm 5$ \\
\hline & Left & $4-26$ & $16 \pm 5$ \\
\hline \multicolumn{4}{|c|}{$\begin{array}{l}n=47 \\
\text { LH, luteinizing hormone; FSH, follicle-stimulating hormone. } \\
\text { Normal reference range } L H: 2.2-8.4 \mathrm{mlU} / \mathrm{ml} \text {; FSH: } 1.8-12.0 \mathrm{mlU} / \mathrm{ml} \text {; } \\
\text { Testosterone: } 225-1040 \mathrm{ng} / \mathrm{dl} \text {. }\end{array}$} \\
\hline
\end{tabular}

\section{Sperm preparation}

Semen samples were obtained at start of the study and after 2 and 4 months. After at least 2 days of sexual abstinence, ejaculates were obtained by masturbation in sterile plastic containers. After liquefaction at room temperature, semen volume was determined and samples were immediately examined microscopically according to the guidelines of the WHO (3). Motility of spermatozoa was investigated at $37^{\circ} \mathrm{C}$ and given as average motility rate. Each specimen was investigated by two laboratory technicians.

\section{Erectile function}

To evaluate the influence of Edicare ${ }^{\circledR}$ on erectile function, participants answered to the questions contained in the International Index of Erectile Function (IIEF) in the extended version with 15 questions (11). The questionnaire of IIEF, translated into Japanese, was provided to the subjects for assessment before the start of the study, at 4 weeks and again at 8 weeks. We examined the total score of IIEF, IIEF5, and each domain: Erectile Function (EF); Orgasmic Function (OF); Sexual Desire (SD); Intercourse Satisfaction (IS); and Overall Satisfaction (OS).

\section{Supplement use}

The commercialized food supplement Edicare ${ }^{\circledR}$ (manufactured by Kobayashi Pharmaceutical Co., Ltd.) containing $10 \mathrm{mg}$ of Pycnogenol, $115 \mathrm{mg}$ of L-arginine and $92 \mathrm{mg}$ of aspartic acid per tablet was used in the present study. The subjects were asked to take six tablets each day and to record their supplement intake in a diary.

\section{Statistical analysis}

The student's t-test was employed for inter-group comparison of the change in IIEF and each domain scores using the Statcel 3 program (OMS Publishing, 2011, Japan). For seminal parameters Wilcoxon's signed rank sum test was used for intra-group comparisons, and differences in mean values were assayed. In each case, the level of statistical significance was set at $\mathrm{p}<0.05$.

\section{RESULTS}

Baseline values of the participants are given in Table 1 . Testosterone levels are partly below, LH and FSH are

Table 2.

Sperm variables throughout the study.

\begin{tabular}{|lccc|}
\hline \multicolumn{3}{c|}{ Mean \pm SD } \\
\hline \multicolumn{3}{c}{ B months } & 4 months \\
\hline Semen volume $(\mathrm{ml})$ & $3.02 \pm 1.55$ & $2.69 \pm 1.38$ & $2.63 \pm 1.42$ \\
p-value & & 0.12 & 0.09 \\
Sperm concentration & & & \\
$\left(\times 10^{6} / \mathrm{ml}\right)$ & $11.79 \pm 9.86$ & $21.22 \pm 28.17$ & $20.15 \pm 23.99$ \\
$p$-value & & $* 0.02$ & $* 0.01$ \\
Sperm motility $(\%)$ & $32.31 \pm 24.47$ & $35.42 \pm 23.71$ & $33.81 \pm 21.46$ \\
p-value & & 0.15 & 0.08 \\
\hline$*: p<0.05$. & & \multicolumn{3}{c}{ Wilcoxon signed-ranks test } \\
\hline
\end{tabular}


Table 3.

Scores for Erectile Function - IIEF.

\begin{tabular}{|lccc|}
\hline \multicolumn{4}{c}{ Mean \pm SD } \\
\hline OS & Baseline & After treatment & p-values \\
IS & $7.36 \pm 1.55$ & $7.63 \pm 1.23$ & 0.12 \\
SD & $9.02 \pm 3.18$ & $9.13 \pm 3.94$ & 0.11 \\
OF & $6.86 \pm 1.46$ & $6.95 \pm 1.83$ & 0.69 \\
EF & $9.01 \pm 1.92$ & $9.34 \pm 1.66$ & $* 0.03$ \\
Total & $25.43 \pm 5.90$ & $26.36 \pm 6.14$ & 0.08 \\
IIEF5 & $57.69 \pm 11.04$ & $59.43 \pm 12.57$ & $* 0.02$ \\
\hline *: $p<$ 0.05. & $21.26 \pm 4.75$ & $21.47 \pm 5.67$ & 0.25 \\
OS: Overall Satisfaction, IS: Intercourse Satisfaction, SD: Sexual Desire, \\
OF: Orgasmic Function, EF: Erectile Function \\
\hline
\end{tabular}

partly high but the mean is in the normal range. Supplementation with the combination of L-arginine and French maritime pine bark extract effectively increased the average sperm concentration significantly after 2 and 4 months (Table 2). Furthermore, there was a slight, but not significant improvement in the motility rate and the number of functioning sperms after supplementation for 4 months. During the initial screening, volunteers showed a mild erectile dysfunction according to IIEF. Erectile function was significantly ameliorated after 4 months according to the answers of the participants in the total score of IIEF and domain of OF (Table 3).

\section{Discussion}

Several approaches have been proposed for the management of infertility and ED caused by oxidative stress. Once an individual has been identified as having oxidative stress-related reproduction and sexual dysfunction, treatment should be aimed at identification and amelioration of the underlying cause before considering antioxidant treatment.

Lifestyle behaviors such as smoking, poor diet, alcohol abuse, pollution and environmental toxins, obesity, and psychological stress have all been linked to oxidative stress. While the effectiveness of eliminating these lifestyle triggers on oxidative stress has not been formally tested, it is likely that making positive lifestyle changes such as changing to a diet high in fruit and vegetables, maintaining normal weight, and reducing smoking or alcohol intake would have at least some beneficial effects on sperm health.

Several studies have reported that levels of reactive oxygen species within semen can be reduced by augmenting the scavenging capacity of seminal plasma using oral antioxidant supplements (7).

The obtained results show the positive effect of the combination of L-arginine and Pycnogenol ${ }^{\circledR}$ in Edicare ${ }^{\circledR}$ on sperm function and erectile function. The dosage of Larginine $690 \mathrm{mg}$ and Pycnogenol ${ }^{\circledR} 60 \mathrm{mg}$ used in this investigation was considerably lower than the amounts of L-arginine and Pycnogenol ${ }^{\circledR}$ given in previous studies of Stanislavov and Nikolova with $1.43 \mathrm{~g}$ L-arginine and $120 \mathrm{mg}$ Pycnogenol ${ }^{\circledR}(4,5)$.
A comparison of the results of the present study with the studies with the higher dosage indicate that the lower dosage is less effective.

The assumption, that the lower body weight of Japanese men compared to Bulgarian men will compensate the lower dosage is not fully justified.

In principle, the combination of Pycnogenol ${ }^{\circledR}$ and L-arginine acts by increasing the production of $\mathrm{NO}$ from Larginine. As has been demonstrated with healthy Japanese volunteers that Pycnogenol ${ }^{\circledR}$ activates the endothelial nitric oxide synthase (e-NOS) (12). An enhanced activity of e-NOS plus a high concentration of its substrate L-arginine results in a greater production of NO. NO is activating guanylate cyclase to produce cGMP. The cGMP-protein kinase G singling pathway leads to an increase of sperm motility (13).

Another positive effect of Pycnogenol ${ }^{\circledR}$ is based on its inhibition of inducible nitric oxide synthase (i-NOS) (14). This enzyme is over-expressed in OAT and causes oxidative damage of the sperms. As Pycnogenol ${ }^{\circledR}$ is a potent antioxidant (7) and inhibitor of i-NOS, it is reasonable to assume that the supplementation with Edicare $^{\circledR}$ is able to reduce the damage of sperms of the patients with OAT syndrome.

These effects led the improvement of ED.

As no unwanted effects were observed or reported from patients, Edicare ${ }^{\circledR}$ may considered as a safe natural product which helps to improve fertility in men with OAT syndrome.

\section{Contributions}

All authors participated in the experimental design and method, and the collection, analysis and interpretation of the data.

\section{REFERENCES}

1. Jungwirth A, Giwercman A, Tournaye $H$ et al. European Association of Urology Guidelines on Male Infertility: The 2012 Update. Eur Urol. 2012; 62:324-332.

2. Iwamoto T, Nozawa S, Mieno MN, et al. Semen quality of 1559 young men form four cities in Japan: a cross-sectional populationbased study. BMJ open. 2013; 3: e 00222 doi: 1136/bmj open-2012002222.

3. WHO Manual for Examination and Processing of Human Semen. 5th Ed. WHO 2010.

4. Stanislavov R, Nikolova V, Rohdewald P. Improvement of erectile function with Prelox ${ }^{\circledR}$ : a randomized, double-blind, placebo-controlled, cross-over trial. Int J Impot Res. 2008; 20:173-180.

5. Stanislavov $R$, Rohdewald P. Sperm quality in men is improved by supplementation with a combination of L-arginine, L-citrullin, roburins and Pycnogenol ${ }^{\circledR}$. Minerva Urol Nefrol. 2014; 66:217-23.

6. Stanislavov R, Nikolova V, Rohdewald P. Improvement of Seminal Parameters with Prelox ${ }^{\circledR}$ : A randomized, double-blind, placebocontrolled, cross-over trial. Phytother Res. 2009; 23:297-302.

7. Rohdewald P. A review of the French maritime pine bark extract (Pycnogenol ${ }^{\circledR}$ ), a herbal medication with a diverse pharmacology. Int J Clin Pharmacol Ther. 2002; 40:158-168.

8. Stanislavov R, Nikolova V. Treatment of erectile dysfunction 
with Pycnogenol ${ }^{\circledR}$ and L-arginine. J Sex Marital Ther. 2003; 29:207-213.

9. Lamm S. Prelox ${ }^{\circledR}$ for Improvement of Erectile Quality. Eur J Endocrinol. 2009; 4:70-74.

10. Aoki H, Nagao J, Ueda T, et al. Clinical assessment of a supplement of Pycnogneol and L-arginine in Japanese patients with mild to moderate erectile dysfunction. Phytother Res. 2012; 26:204-207.

11. Rosen RC, Cappelleri JC, Gendrano N 3rd. The International Index of Erectile Function (IIEF): A state of the science review. Int $J$ Impot Res. 2002; 14:226-244.
12. Nishioka K, Hidaka T, Nakamura S, et al. Pycnogenol, French Maritime Pine Bark Extract, Augments Endothelium-Dependent Vasodilation in Humans. Hypertens Res. 2007; 30:775-780.

13. O'Bryan MK, Zini A, Cheng CY, et al. Human endothelial nitric oxide synthase expression: correlation with sperm motility. Fertil Steril. 1998; 70:1143-1147.

14. Uhlenhut k, Högger P. Facilated cellular uptake and suppression of iducible nitric oxide synthase by a metabolite of maritime pine bark extract (Pycnogenol $^{\circledR}$ ). Free Radic Biol Med. 2012: 53:305-313.

\section{Correspondence}

Yoshitomo Kobori, MD (Corresponding Author)

ykobori@dokkyomed.ac.jp

Department of Urology, Dokkyo Medical University Koshigaya Hospital

2-1-50 Minami-Koshigaya, Koshigaya, Saitama 343-8555, Japan

Keisuke Suzuki, MD

Toshiyuki Iwahata, MD

Takeshi Shin, MD

Yuko Sadaoka, MD

Ryo Sato, MD

Kojiro Nishio, MD

Hiroshi Yagi, MD

Gaku Arai, MD

Shigehiro Soh, MD

Hiroshi Okada, MD

Department of Urology, Dokkyo Medical University Koshigaya Hospital, Saitama, Japan

\section{Jeffry Michael Strong}

Horphag Research, Cointrin/Geneva, Switzerland

Peter Rohdewald

Institute of Pharmaceutical Chemistry, University of Munster, Munster, Germany 